\title{
Analysis of PR Gene derived Pathogen-Inducible synthetic Promoters in the Crop Sugar Beet
}

\author{
S. Klages', M. Pflugmacher', C. Rohlf', W. Brieß', P. Rushton², C. Kirsch², A. Heise ${ }^{2}$, I. Somssich² and D. J. Stahl' \\ ${ }^{1}$ PLANTA GmbH, Grimsehlstrasse 31, D-37555 Einbeck, Germany \\ ${ }^{2}$ Max-Planck-Institut für Züchtungsforschung, Carl-von-Linné Weg 10, D-50829 Köln, Germany. \\ Correspondence to: D. J. Stahl, PLANTA GmbH, Grimsehlstrasse 31, D-37555 Einbeck, Germany, E-mail: d.stahl@kws.de
}

Eingegangen: 5. September 2005

Different promising strategies to engineer fungal resistance of plants have been developed in the last years. A prerequisite for many concepts is the requirement of pathogen-inducible promoters, which restrict the expression of defence responses to the local infection site.

The development of synthetic pathogen-inducible promoters exclusively containing well defined regulatory cis-elements of PR genes has been described (Rushton et al., 2002). Using the DNA elements W, S, D, Gst1 and E17, a large set of artificial promoters with different properties have been designed. Here we describe the analysis of these promoters in sugar beet after infection with the fungal pathogen Cercospora beticola under in-vitro and greenhouse conditions. Depending on the combination and number of cis-elements, the promoters differed in mediating the strength of reporter gene expression, pathogen inducibility and basal activity. Promoters constructed as chimeric regulatory elements containing two different cis-elements were superior to promoters consisting of a single type of cis-element. In summary, we have identified a set of promoters with different suitable abilities for the development of fungal resistant sugar beets. 